OPEN ACCESS

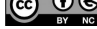

(

CrossMark

${ }^{1}$ Epidemiology Group, Institute

of Applied Health Sciences,

University of Aberdeen,

Aberdeen, UK

${ }^{2}$ Medical Statistics Team,

Institute of Applied Health

Sciences, University of

Aberdeen, Aberdeen, UK

Correspondence to:

S Bhattacharya

Dugald Baird Centre for

Research on Women's Health,

Aberdeen Maternity Hospital,

Aberdeen AB25 2ZL, UK

sohinee.bhattacharya@abdn.

ac.uk

Cite this as: BMJ 2015;350:h3080

doi: 10.1136/bmj.h3080

Accepted: 20 May 2015

\title{
Risk of recurrent stillbirth: systematic review and meta-analysis
}

\author{
Kathleen Lamont, ${ }^{1}$ Neil W Scott, ${ }^{2}$ Gareth T Jones, ${ }^{1}$ Sohinee Bhattacharya ${ }^{1}$
}

\section{ABSTRACT}

OBJECTIVE

To determine the risk of recurrent stillbirth.

DESIGN

Systematic review and meta-analysis of cohort and case-control studies.

\section{DATA SOURCES}

Embase, Medline, Cochrane Library, PubMed, CINAHL, and Scopus searched systematically with no restrictions on date, publication, or language to identify relevant studies. Supplementary efforts included searching relevant internet resources as well as hand searching the reference lists of included studies. Where published information was unclear or inadequate, corresponding authors were contacted for more information.

\section{STUDY SELECTION \\ Cohort and case-control studies from high income countries were potentially eligible if they investigated the association between stillbirth in an initial pregnancy and risk of stillbirth in a subsequent pregnancy. Stillbirth was defined as fetal death occurring at more than 20 weeks' gestation or a birth weight of at least $400 \mathrm{~g}$. Two reviewers independently screened titles to identify eligible studies based on inclusion and exclusion criteria agreed a priori, extracted data, and assessed the methodological quality using scoring criteria from the critical appraisal skills programme. Random effects meta-analyses were used to combine the results of the included studies. Subgroup analysis was performed on studies that examined unexplained stillbirth.}

\section{RESULTS}

13 cohort studies and three case-control studies met the inclusion criteria and were included in the meta-analysis. Data were available on 3412079 women with pregnancies beyond 20 weeks duration, of who 3387538 (99.3\%) had had a previous live birth and $24541(0.7 \%)$ a stillbirth. A total of 14283 stillbirths occurred in subsequent pregnancies, $606 / 24541(2.5 \%)$ in women with a history of stillbirth

\section{WHAT IS ALREADY KNOWN ON THIS TOPIC}

Stillbirth remains a major public health problem

For women with a stillbirth from a known recurrent cause, the risk of stillbirth in a subsequent pregnancy is high

Where the previous stillbirth was unexplained (the most common classification of cause of death), risk of recurrence is unclear

\section{WHAT THIS STUDY ADDS}

The results of this meta-analysis provide evidence to support an increased risk of stillbirth recurrence after a previous stillbirth

The increased risk remained after adjusting for the effects of confounding

The risk of stillbirth after an unexplained stillbirth may not be increased, but at present evidence for this is inadequate and $13677 / 3387538(0.4 \%)$ among women with no such history (pooled odds ratio $4.83,95 \%$ confidence interval 3.77 to 6.18 ). 12 studies specifically assessed the risk of stillbirth in second pregnancies. Compared with women who had a live birth in their first pregnancy, those who experienced a stillbirth were almost five times more likely to experience a stillbirth in their second pregnancy (odds ratio 4.77, $95 \%$ confidence interval 3.70 to 6.15 ). The pooled odds ratio using the adjusted effect measures from the primary studies was 3.38 (95\% confidence interval 2.61 to 4.38). Four studies examined the risk of recurrent unexplained stillbirth. Methodological differences between these studies precluded pooling the results.

\section{CONCLUSIONS}

The risk of stillbirth in subsequent pregnancies is higher in women who experience a stillbirth in their first pregnancy. This increased risk remained after adjusted analysis. Evidence surrounding the recurrence risk of unexplained stillbirth remains controversial.

\section{Introduction}

Over the past two decades many high income countries have achieved substantial reductions in late gestation stillbirths. Norway and the Netherlands show the largest reductions; however, in the United Kingdom the downward trend in stillbirth rates has slowed and become more or less stable. As a result the UK has one of the highest stillbirth rates and is ranked 33rd out of 35 high income countries in Europe, with around one baby in every 200 being stillborn every year. ${ }^{12}$ Stillbirth is one of the most common adverse obstetric outcomes and a traumatic experience for parents yet until recently was largely ignored. ${ }^{3}$ Couples who have experienced a stillbirth need to understand why it happened and want to know the risk for future pregnancies.

The cause of fetal death is complex as there are many contributing and interacting factors. In addition, certain conditions may be associated with stillbirths without directly causing them-for example, well controlled diabetes mellitus. ${ }^{4}$ Thus, for many stillbirths it is difficult to determine the exact cause, and according to classification systems for informing and establishing the likely cause for the loss of the baby these are classified as unexplained. ${ }^{5}$ Because of the considerable number of classification systems currently in use, the proportion of stillbirths classified as unexplained varies widely, from $9.5 \%$ to $50.2 \% .^{6}$ Notably, more recent classification systems $\mathrm{s}^{7-11}$ yield lower proportions of unexplained deaths as they often attribute relatively common conditions such as velamentous insertion of cord as causes of perinatal deaths. At times, stillbirths may be unexplained because of inadequate investigations to determine a cause of death, but even after extensive evaluation many stillbirths remain unexplained. ${ }^{12}$ 
The increased risk for recurrence of pregnancy complications and outcomes is well recognised..$^{13}$ However, the literature on stillbirth recurrence is sparse and inconsistent. Some studies report recurrence risks ranging from twofold to 10-fold, ${ }^{14-16}$ whereas others report no increased risk. ${ }^{1718}$ Although stillbirth is a common obstetric complication its recurrence is rare and it may be that some primary studies lack the power to detect any increase in risk. Furthermore, many causes of stillbirth (for example, placental abruption) are known to recur in subsequent pregnancies, thus increasing the chances of another stillbirth associated with that cause; but in cases where stillbirth remains unexplained there is no consensus about the risk of stillbirth in the next pregnancy. Because of the uncertainty surrounding the recurrent risk for stillbirth it is difficult for clinicians to counsel couples and to know what level of care to provide in subsequent pregnancies.

We reviewed the evidence on the association between stillbirth in an initial pregnancy and risk of stillbirth in subsequent pregnancies. Specifically, we hypothesised that women whose first pregnancy resulted in a stillbirth or an unexplained stillbirth had an increased risk of stillbirth in any subsequent pregnancy compared with women who had a previous live birth. A priori, we restricted our review to primary studies conducted in high income countries to prevent any distortion of findings from variations in clinical practice and access to healthcare.

\section{Methods}

We conducted a systematic review and meta-analysis following the guidelines recommended by the metaanalysis of observational studies. ${ }^{19}$ Two people (SB, KL) independently performed the literature search, data extraction, and quality assessment of the included studies. Any disagreement was resolved by discussion between reviewers or referred to a third reviewer (GTJ) if necessary.

\section{Eligibility criteria}

Eligible studies were those that were cohort or casecontrol studies conducted in high income countries (all countries listed with the World Bank as high income members of the Organisation for Economic Co-operation and Development), ${ }^{20}$ investigated the association between stillbirth or unexplained stillbirth in an initial pregnancy and risk of stillbirth in a subsequent pregnancy, used a definition of stillbirth as occurring at 20 weeks gestation or more or a birth weight of $400 \mathrm{~g}$ or more; and reported estimates of either odds ratio, risk ratio, or hazard ratio, or provided sufficient data for these to be calculated.

\section{Search strategy}

With guidance from a librarian we searched a range of electronic bibliographic databases: Medline and Embase through Ovid (1946 to 12 September 2014), the Cochrane Library through Wiley Interscience, Cumulative Index to Nursing and Allied Health Literature (CINAHL) through EBSCO Host, PubMed through the National Center for Biotechnology Information (NCBI), and SCOPUS through Elsevier. During preliminary searches we found that the two concepts of stillbirth and recurrence were more often included in journal abstracts or indexed. Therefore the search strategy stemmed from these two concepts. We used a combination of Medical Subject Headings key words, and text words for "stillbirth", "recurrence”, "pregnancy", and "risk factors" that appeared in abstracts and titles. No restrictions were applied to date, publication, or language, although we limited studies to those in human participants. Also, the term "unexplained" was not included in the search strategy. The search strategy was initially developed for use in Medline and was then adapted for searching the other databases (see supplementary file for the search strategies used in each database). In addition, we searched the UK Research Clinical Network Portfolio Database, ${ }^{21}$ the MIDIRS website (a broad reference resource available to obstetricians, midwives, and consumers), ${ }^{22}$ and the Proquest Dissertations and Theses: UK and Ireland database. ${ }^{23}$ We screened the reference lists of all identified studies obtained as full reports, and we also performed searches using Google search engine in an attempt to find pages that might have provided references. If published papers had inadequate or unclear data we contacted the study authors for further information or clarification.

\section{Data extraction and quality assessment}

Data extraction was accomplished using two data extraction forms; one that included general study characteristics and one that included sample characteristics, stillbirth rates, and measure of association.

Study quality was assessed using the criteria of the critical appraisal skills programme. ${ }^{2425}$ The questions assess study validity, risk of bias in recruitment, exposure and outcome measurement, confounding factors, the reporting of results, and the transferability of results. Scores range from 0-11 for case-control studies and from 0-12 for cohort studies, where a higher score indicates higher quality.

\section{Statistical analysis}

Meta-analyses were conducted using Revman 5.2 (Cochrane Collaboration 2012). ${ }^{26}$ We performed several analyses and present pooled estimated effect sizes using random effects models to incorporate heterogeneity within and between studies. ${ }^{27}$ Firstly, we computed a pooled odds ratio by using the Mantel-Haenszel method to combine the raw data from all studies. ${ }^{28} 29$ Secondly, we pooled the odds ratios from all studies that provided data adjusted for various potential confounding variables. This was done using the generic inverse weighted method-that is, studies were weighted by the inverse of the standard error of the log transformed odds ratios. ${ }^{30}$ We calculated the standard errors of these log odds ratios using published confidence intervals and then used these to weight the studies according to the precision of the odds ratio. To explore the definition of stillbirth as a potential source of heterogeneity we conducted a sensitivity analysis.

Statistical heterogeneity was assessed using the Cochran's $\chi^{2}$ test, and the $I^{2}$ statistic used to summarise the 
degree of variation across studies. As recommended by the Cochrane handbook for systematic reviews, ${ }^{30}$ we considered an $\mathrm{I}^{2}$ value of $0-40 \%$ to represent low heterogeneity, 30-60\% moderate heterogeneity, 50-90\%, substantial heterogeneity, and $75-100 \%$ considerable heterogeneity.

Assuming there is a causal relation between a risk factor and a disease, the population attributable risk is the proportion of disease or deaths in a population that can be attributed to an exposure. We calculated the population attributable risk (odds ratios were used to estimate the relative risk) using a previously published formula. ${ }^{31}$ The likelihood of publication bias was assessed by visual inspection of a funnel plot. ${ }^{32}$

\section{Patient involvement}

There was no patient involvement in this study.

\section{Results}

The database searches returned 6599 potentially relevant unique citations. In addition, one study and a conference abstract were identified through supplementary searches (fig 1). Of these, 38 were selected for further appraisal. Twenty two citations from these did not meet the inclusion criteria and thus were excluded. Thirteen cohort studies $^{141517183334-41}$ and three case-control studies $^{42-44}$ met the inclusion criteria. All of the included studies except for two reported odds ratios-one reported a hazard ratio ${ }^{18}$ and the other a relative risk. ${ }^{43}$ Because the outcome of interest is rare, the odds ratio, relative risk, and hazard ratio approximate each other. ${ }^{29}$ Fourteen authors were contacted for information.

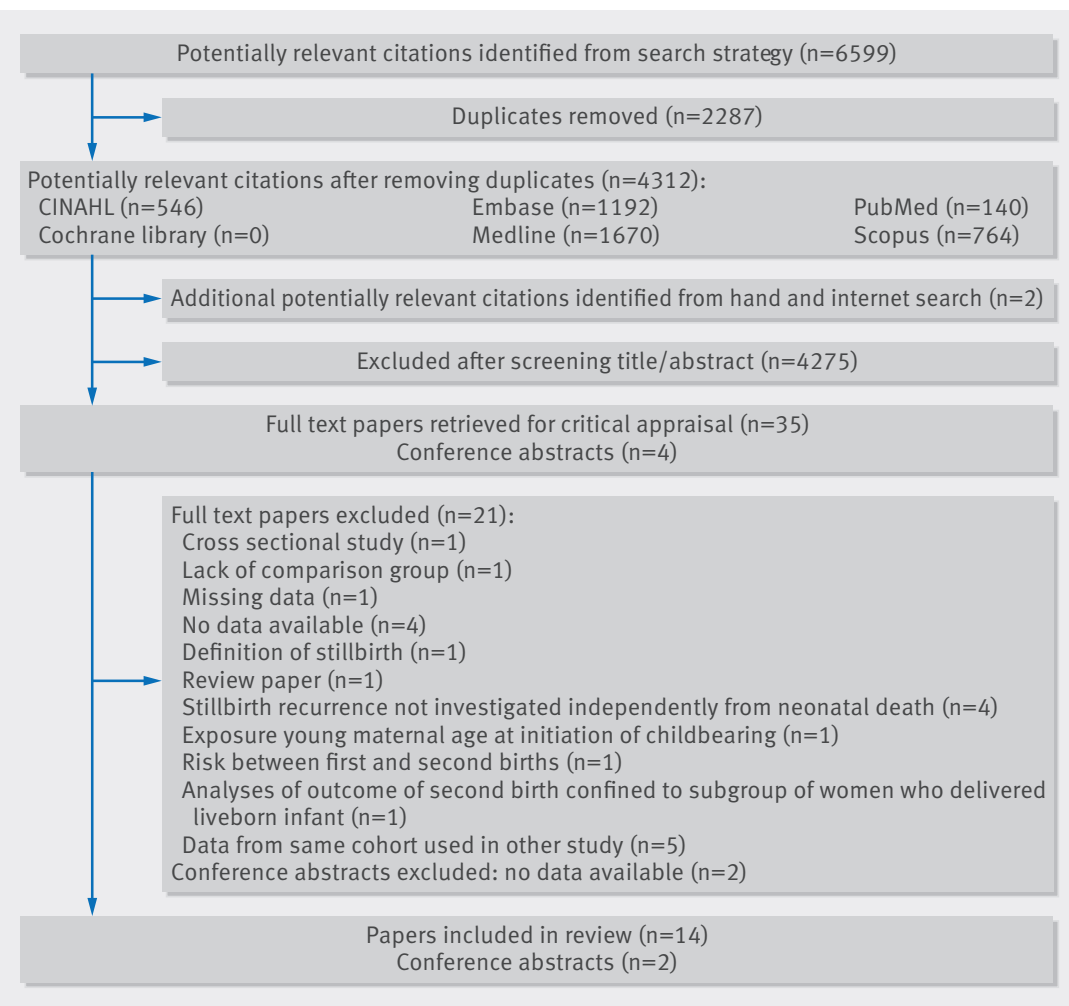

Fig 1 | Search results and process for identification, selection, and inclusion of references in systematic review
Eleven responded, with three providing additional data that were included in the analysis. 353940

\section{Quality assessment}

The quality appraisal scores using the critical appraisal skills programme for all 13 cohort studies were high; median quality score 10.50, with a range of 9.5-11.5 (see supplementary appendix table 1). The median quality score for case-control studies was 8.5, with a range of 7-8.5 (see supplementary appendix table 2). These results showed that the observational studies were of good quality. Twelve studies reported adjusted odds ratios for the association between stillbirth in an initial pregnancy and risk of stillbirth in a subsequent pregnancy. Most studies adjusted for maternal age, smoking, and socioeconomic status. Adjustment for other potential confounders such as living with a partner or marital status, education, race or ethnicity, and interval between pregnancies varied among the studies, with two studies adjusting for body mass index. ${ }^{1517}$ Six studies that investigated the risk of stillbirth recurrence adjusted for obstetric complications such as pre-eclampsia, placental abruption, or preterm birth medical, ${ }^{14171841}$ or obstetric risk factors. ${ }^{3337}$ One of those studies ${ }^{41}$ reported two adjusted odds ratios, one that included gestational age (model 1) and one that excluded gestational age in the logistic regression model (model 2).

\section{Study characteristics}

Tables 1 and 2 show the general study characteristics and sample characteristics of included studies. Studies were published between 2001 and 2014 and five were conducted in Australia, ${ }^{183840-42}$ three in Scotland, ${ }^{14} 1739$ three in the United States, 153344 and one each in Denmark, ${ }^{35}$ Israel, ${ }^{43}$ the Netherlands, ${ }^{37}$ Norway, ${ }^{36}$ and Sweden. ${ }^{34}$ All articles were in English. Nine of the cohort studies were large population based studies that included data extending over at least 10 years. One of these ${ }^{36}$ included data collected over nearly 40 years, thus the combined data collection period spanned from 1967 to 2009. Eleven of the cohort studies examined the risk of stillbirth recurrence in a second pregnancy. In one of the remaining cohort studies, data were available on a subset of women on their first and second sequential births. ${ }^{40}$ The remaining cohort study examined risk of recurrence of unexplained stillbirth and included women in the exposed group with an unexplained stillbirth that need not necessarily have been their first birth. All case-control studies included women with more than two pregnancies. ${ }^{42-44}$

\section{Exposure in the included studies}

Ascertainment of stillbirth was confirmed through nationwide registers, ${ }^{1434-4042}$ hospital databases, ${ }^{1517183341-44}$ and hospital records. ${ }^{4244}$ Seven studies used the World Health Organization international classification of disease codes to classify maternal conditions and obstetric complications. ${ }^{14173335363940}$ Studies used a variety of different definitions of stillbirth, with most of the studies defining stillbirth from an early gestational age ( $\geq 20$ weeks), 15171833353638414244 whereas others used a later gestation ( $\geq 22$ weeks, ${ }^{3743} \geq 24$ weeks, ${ }^{1439}$ and $\geq 28$ weeks). ${ }^{34}$ The remaining study ${ }^{40}$ used 


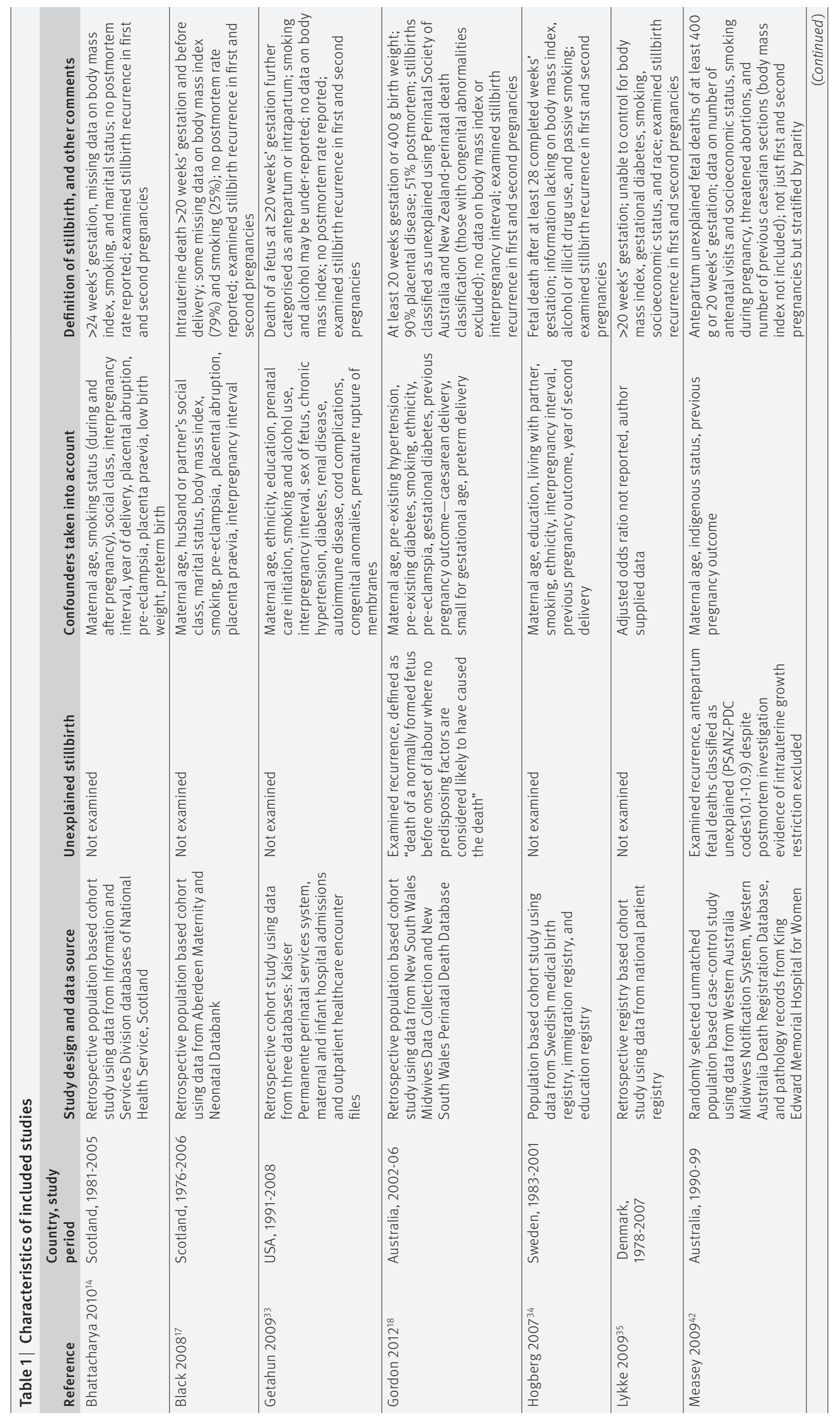

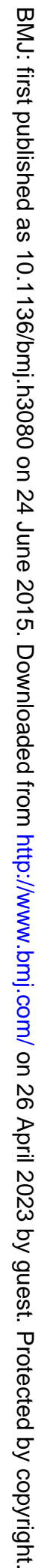




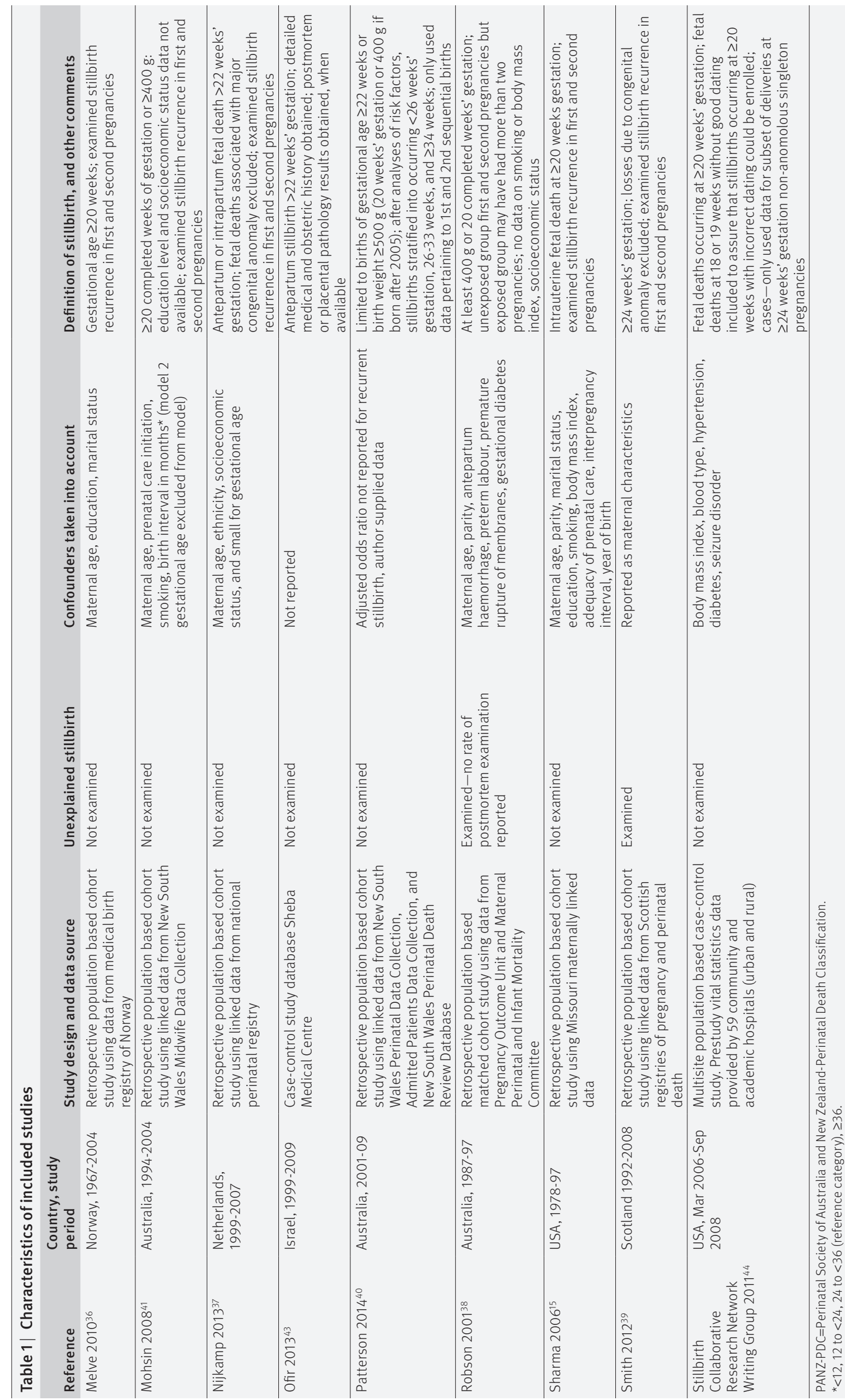

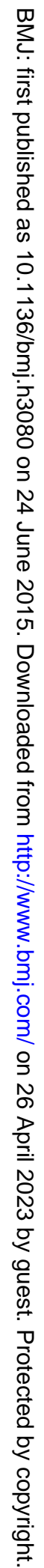




\begin{tabular}{|c|c|c|c|c|c|c|c|c|c|}
\hline \multirow[b]{2}{*}{ Reference } & \multirow[b]{2}{*}{$\begin{array}{l}\text { Population } \\
\text { size }\end{array}$} & \multirow{2}{*}{$\begin{array}{l}\text { No (\%) with } \\
\text { previous } \\
\text { stillbirths }\end{array}$} & \multirow{2}{*}{$\begin{array}{l}\text { No with } \\
\text { previous } \\
\text { live birth }\end{array}$} & \multirow{2}{*}{$\begin{array}{l}\text { Stillbirth } \\
\text { rate in 1st } \\
\text { pregnancy }\end{array}$} & \multicolumn{2}{|c|}{$\begin{array}{l}\text { No (\%) with } \\
\text { subsequent stillbirth }\end{array}$} & \multicolumn{2}{|c|}{$\begin{array}{l}\text { Stillbirth rate in } 2 \mathrm{nd} \\
\text { pregnancy }\end{array}$} & \multirow[b]{2}{*}{ Measure of association* } \\
\hline & & & & & $\begin{array}{l}\text { Previous } \\
\text { stillbirth }\end{array}$ & $\begin{array}{l}\text { Previous } \\
\text { live birth }\end{array}$ & $\begin{array}{l}\text { Previous } \\
\text { stillbirth }\end{array}$ & $\begin{array}{l}\text { Previous } \\
\text { live birth }\end{array}$ & \\
\hline Bhattacharya $2010^{14}$ & 309304 & $2677(0.9)$ & 306627 & $8.7 / 1000$ & $50(1.9)$ & $1309(0.4)$ & $18.7 / 1000$ & $4.3 / 1000$ & $\begin{array}{l}\text { Unadjusted odds ratio } 4.44(99 \% \mathrm{Cl} 3.34 \\
\text { to } 5.90) \text {; adjusted odds ratio } 1.94(99 \% \mathrm{Cl} \\
1.29 \text { to } 2.92)\end{array}$ \\
\hline Black $2008^{17}$ & 34079 & $364(1.1)$ & 33715 & $10.7 / 1000$ & $5(1.4)$ & $179(0.5)$ & $13.7 / 1000$ & $5.3 / 1000$ & $\begin{array}{l}\text { Unadjusted odds ratio } 2.6 \text { (1.1 to } 6.4) \text {; } \\
\text { adjusted odds ratio } 1.2 \text { (0.4 to } 3.4)\end{array}$ \\
\hline Getahun $2009^{33}$ & 71315 & $373(0.5)$ & 70942 & $5.2 / 1000$ & $5(1.3)$ & $257(0.4)$ & $13.4 / 1000$ & $3.6 / 1000$ & $\begin{array}{l}\text { Unadjusted odds ratio } 3.74 \text { (1.53 to 9.11); } \\
\text { adjusted odds ratio } 3.5 \text { (1.9 to } 6.9 \text { ) }\end{array}$ \\
\hline Gordon $2012^{18}$ & 52110 & $348(0.67)$ & 51762 & $6.7 / 1000$ & $3(0.9)$ & $145(0.3)$ & $8.6 / 1000$ & $2.8 / 1000$ & $\begin{array}{l}\text { Unadjusted odds ratio } 3.10 \text { (0.98 to 9.76); } \\
\text { adjusted hazard ratio } 2.03 \text { (0.6 to } 6.9 \text { ) }\end{array}$ \\
\hline Hogberg $2007^{34}$ & 526691 & $2363(0.45)$ & 524328 & $4.5 / 1000$ & $18(0.8)$ & $1402(0.3)$ & $7.6 / 1000$ & $2.7 / 1000$ & $\begin{array}{l}\text { Unadjusted odds ratio } 2.86 \text { (1.80 to } 4.57) \text {; } \\
\text { adjusted odds ratio } 2.4 \text { (1.32 to } 4.41)\end{array}$ \\
\hline Lykke $2009^{35}$ & 536419 & $3161(0.6)$ & 533258 & $5.9 / 1000$ & $106(3.35)$ & $\begin{array}{l}1832 \\
(0.34)\end{array}$ & $33.5 / 1000$ & $3.4 / 1000$ & $\begin{array}{l}\text { Unadjusted odds ratio } 10.06 \text { ( } 8.25 \text { to } \\
\text { 12.28); data supplied by author (not } \\
\text { reported) }\end{array}$ \\
\hline Melve $2010^{36}$ & 574311 & $5996(1.0)$ & 568315 & $10.4 / 1000$ & $222(3.7)$ & $3,507(0.6)$ & $37 / 1000$ & $6.2 / 1000$ & $\begin{array}{l}\text { Unadjusted odds ratio } 6.2 \text { (5.4 to } 7.1) \text {; } \\
\text { adjusted odds ratio } 4.5 \text { (2.9 to } 7.1)\end{array}$ \\
\hline Measey $2009^{42}$ & 852 & 167 & 685 & NA & $7(4.2)$ & $8(1.2)$ & $41.9 / 1000$ & $11.7 / 1000$ & $\begin{array}{l}\text { Unadjusted odds ratio } 4.42 \text { (1.56 to } 12.53) \text {; } \\
\text { adjusted odds ratio } 4.18 \text { (1.36 to } 12.89)\end{array}$ \\
\hline Mohsin $2008^{41}$ & 244840 & $2168(0.9)$ & 242672 & $9 / 1000$ & $72(3.3)$ & $1144(0.5)$ & $33 / 1000$ & $4.7 / 1000$ & $\begin{array}{l}\text { Unadjusted odds ratio } 7.25 \text {, adjusted odds } \\
\text { ratio model } 2^{*} 3.56(2.76 \text { to } 4.59)\end{array}$ \\
\hline Nijkamp $2013^{37}$ & 252827 & $2058(0.81)$ & 250769 & $8.1 / 1000$ & $12(0.58)$ & $803(0.32)$ & $5.8 / 1000$ & $3.2 / 1000$ & $\begin{array}{l}\text { Unadjusted odds ratio } 1.8 \text { (1.02 to } 3.60) \text {; } \\
\text { adjusted odds ratio } 2.4 \text { (1.32 to } 4.21)\end{array}$ \\
\hline Ofir $2013^{43}$ & 10480 & 73 & 10370 & NA & $5(6.8)$ & $32(0.31)$ & $68.5 / 1000$ & $3.1 / 1000$ & Odds ratio 22.2 (8.9 to 55.4) \\
\hline Patterson $2014^{40}$ & 145437 & 863 & 144098 & $5.9 / 1000$ & $12(1.39)$ & $464(0.32)$ & $14 / 1000$ & $3.2 / 1000$ & $\begin{array}{l}\text { Data supplied by author (not reported), } \\
\text { unadjusted odds ratio } 4.3 \text { ( } 2.3 \text { to } 7.8 \text { ); } \\
\text { adjusted odds ratio not calculated }\end{array}$ \\
\hline Robson 38 & 3476 & 316 & 3160 & NA & 2 & 20 & $6.3 / 1000$ & $6.3 / 1000$ & $\begin{array}{l}\text { Adjusted odds ratio as only unexplained } \\
\text { stillbirth, } 1.0(0.23 \text { to } 4.30)\end{array}$ \\
\hline Sharma $2006^{15}$ & 404180 & $1979(0.5)$ & 402201 & $4.9 / 1000$ & $45(2.3)$ & $1884(0.5)$ & $22.7 / 1000$ & $4.7 / 1000$ & $\begin{array}{l}\text { Unadjusted odds ratio 4.9; adjusted odds } \\
\text { ratio } 4.7 \text { ( } 3.3 \text { to } 6.6 \text { ) }\end{array}$ \\
\hline Smith $2012^{39}$ & 244204 & 1323 & 242881 & $5.4 / 1000$ & $21(1.59)$ & $660(0.27)$ & $15.9 / 1000$ & $2.7 / 1000$ & $\begin{array}{l}\text { Unadjusted odds ratio } 5.9 \text { (3.8 to 9.2); } \\
\text { adjusted odds ratio } 5.8 \text { (3.7 to 9.0) }\end{array}$ \\
\hline $\begin{array}{l}\text { Smith 2012,39 } \\
\text { unexplained } \\
\text { stillbirth }\end{array}$ & 244204 & 1323 & 242881 & $5.4 / 1000$ & $8(0.6)$ & $461(0.19)$ & $6 / 1000$ & $1.9 / 1000$ & $\begin{array}{l}\text { Data supplied by author (not reported), } \\
3.2 \text { (1.59 to } 6.45)\end{array}$ \\
\hline $\begin{array}{l}\text { Stillbirth } \\
\text { Collaborative } \\
\text { Research Network } \\
\text { Writing Group } 2011^{44}\end{array}$ & 1591 & 303 & 1288 & NA & $21(6.8)$ & $18(1.4)$ & $69.3 / 1000$ & $14 / 1000$ & $\begin{array}{l}\text { Unadjusted odds ratio not reported, } \\
\text { adjusted odds ratio } 6.67 \text { (3.14 to 14.17) }\end{array}$ \\
\hline
\end{tabular}

NA=not available.

${ }^{*} 95 \%$ confidence intervals apply unless stated otherwise.

*Model 2: gestational age excluded from model.

a combination of at least 22 weeks' gestation or at least 20 weeks if the infant was born after 2005, reflecting a change in reporting requirements. A birth weight defined as at least $400 \mathrm{~g}$ was also included in two studies ${ }^{1841}$ and $400 \mathrm{~g} / 500 \mathrm{~g}$ in the study that used the combined definition of at least 20/22 weeks' gestation. ${ }^{40}$

\section{Studies that examined risk of recurrence of unexplained stillbirth}

Only three of the cohort ${ }^{18} 3839$ and one of the casecontrol $^{42}$ studies examined risk of recurrence of unexplained stillbirth. Two of these $\mathrm{e}^{1842}$ identified the causes of stillbirth using the perinatal death classification system of the Perinatal Society of Australia and New Zealand (PSANZ-PDC). ${ }^{10} 11$ One of the others ${ }^{38}$ used a modification of Whitfield. ${ }^{45}$ The remaining study by Smith $^{39}$ was a conference publication and the author informed us that the Wigglesworth classification, the most frequently used classification system in high income countries, was applied.

\section{Quantitative data synthesis}

Data were available on 3412079 women comprising 3387538 (99.3\%) who had a live birth and 24541 (0.7\%) who had a stillbirth in an initial pregnancy. A total of 14283 stillbirths occurred in the subsequent pregnancy, $606 / 24541(2.5 \%)$ in women with a history of stillbirth and $13677 / 3387538(0.4 \%)$ in women with no such history.

Figure 2 shows the unadjusted risk of stillbirth recurrence in women who had experienced a previous stillbirth in any pregnancy compared with those with no such history. A considerable amount of heterogeneity between studies was indicated $\left(\mathrm{I}^{2}=82 \%, \mathrm{P}<0.01\right)$. Odds ratios from individual studies ranged from 1.00 to 23.75 , with a clear suggestion of increased odds of subsequent stillbirth among women who experienced stillbirth in a previous pregnancy (pooled odds ratio 4.83 , 95\% confidence interval 3.77 to 6.18 ). When the analysis was restricted to only studies that examined risk of stillbirth recurrence in women with first and second subsequent pregnancies the risk was slightly less than the 
Fig 2 | Random effects model (unadjusted) showing risk of recurrent stillbirth associated with previous stillbirth. SCRNWG=Stillbirth Collaborative Research Network Writing Group

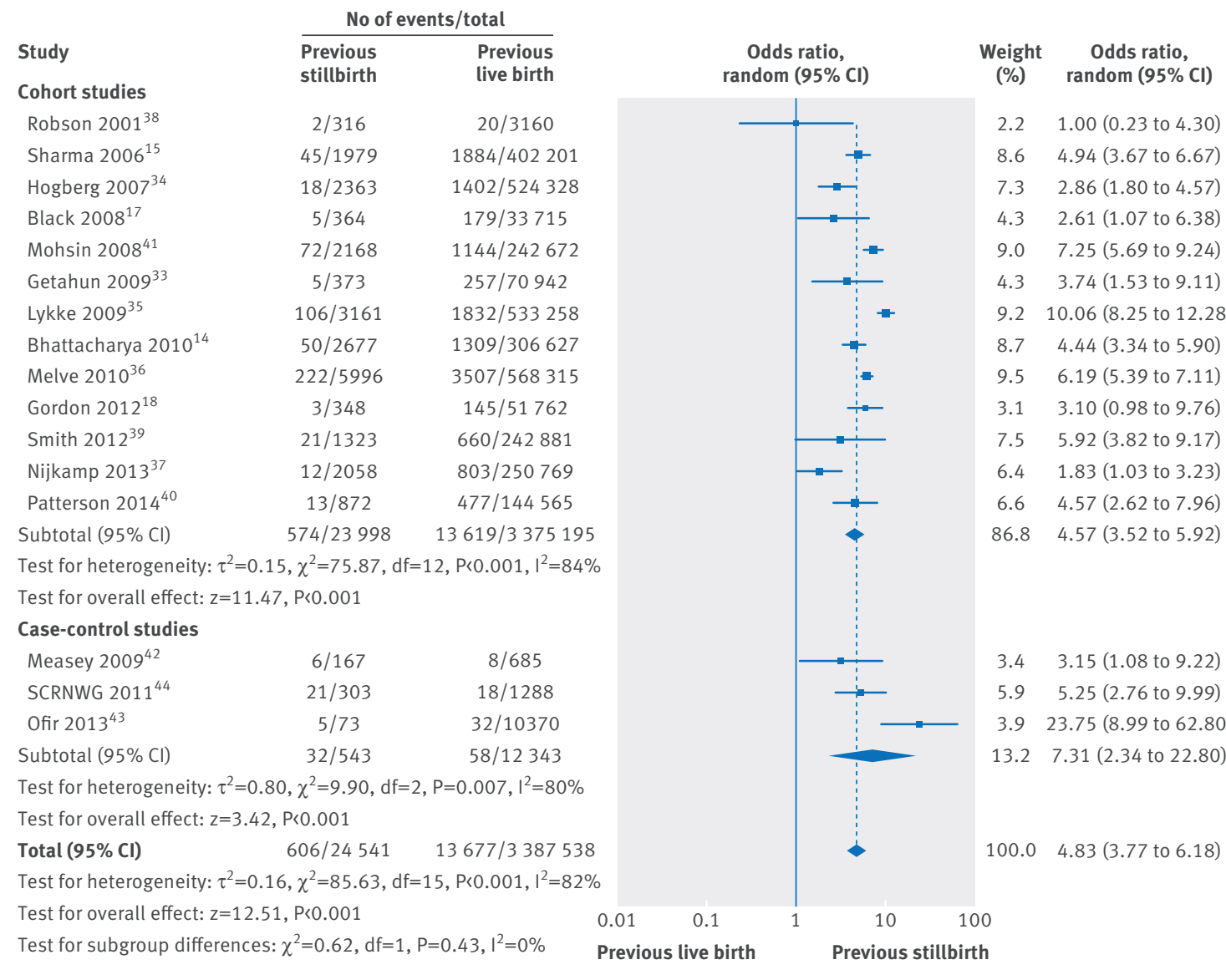

unrestricted pooled odds ratio (4.77-fold, $95 \%$ confidence interval 3.70-fold to 6.15-fold) (fig 3).

Using only the adjusted odds ratios reported in primary studies, the increased effect of a previous stillbirth remained (pooled odds ratio 3.38, 95\% confidence interval 2.61 to 4.38) (fig 4). The pooled unadjusted odds ratio for these studies was 4.44 (95\% confidence interval 3.54 to 5.56 ).

\section{Subgroup analysis}

Because of methodological differences between studies that examined risk of recurrent unexplained stillbirth we were unable to perform the prespecified subgroup analysis. Four studies examined the recurrence risk of unexplained stillbirth. Two of these studies conducted a prospective analysis looking at risk of stillbirth recurrence (explained and unexplained) after a previous unexplained stillbirth. ${ }^{1838}$ The reported adjusted risks for stillbirth in a subsequent pregnancy after previous unexplained stillbirth in these two studies were 3.11 (95\% confidence interval 0.72 to 13.50$)^{18}$ and $1.00(0.23$ to 4.30$) .{ }^{38} \mathrm{~A}$ retrospective analysis looked at risk of unexplained stillbirth in a subsequent pregnancy after any previous explained or unexplained stillbirth..$^{39} 42$ The reported adjusted risk for unexplained stillbirth after any stillbirth in one of the studies $^{42}$ was 4.18 (95\% confidence interval 1.36 to 12.89). The other study did not report the odds ratio in the conference abstract, but the author provided the data. ${ }^{39}$ For this study the adjusted risk for unexplained stillbirth after any stillbirth was 3.20 (95\% confidence interval 1.59 to 6.45 ).

\section{Sensitivity analyses}

To examine possible sources of heterogeneity across studies, we performed a sensitivity analysis according to definition of stillbirth, but this did not explain much of the heterogeneity. As data overlapped slightly (as little as $8 \%$ ) between the studies by Black and colleagues ${ }^{17}$ and Bhattacharya and colleagues, ${ }^{14}$ we conducted a sensitivity analysis by removing Black and colleagues' studythe rationale being that Bhattacharya and colleagues' findings were considered more generalisable because of the population based design. This resulted in a slightly larger overall pooled odds ratio $(4.97,3.87$ to 6.38$)$.

As we were interested in potentially modifiable risk factors, we also performed an analysis that included the studies that adjusted only for maternal characteristics. Again there was a clear suggestion of an increased odds of subsequent stillbirth in women who had experienced stillbirth in a previous pregnancy (pooled unadjusted odds ratio 5.48-fold, 95\% confidence interval 4.42-fold to 6.79-fold). After adjusting only for maternal factors, the increased risk was slightly attenuated (pooled odds ratio $4.27,95 \%$ confidence interval 3.38 to 5.39 ). Ofir and colleagues ${ }^{43}$ reported an exceptionally high odds ratio, of 23.75 (95\% confidence interval 8.99 to 62.80 ). We therefore examined the effect of removing this study from the meta-analysis and found the pooled odds ratio to be reduced slightly, to 4.56 (95\% confidence interval 
Fig 3 | Random effects model (unadjusted) showing risk of recurrent stillbirth associated with previous stillbirth restricted to women with first and second subsequent pregnancies

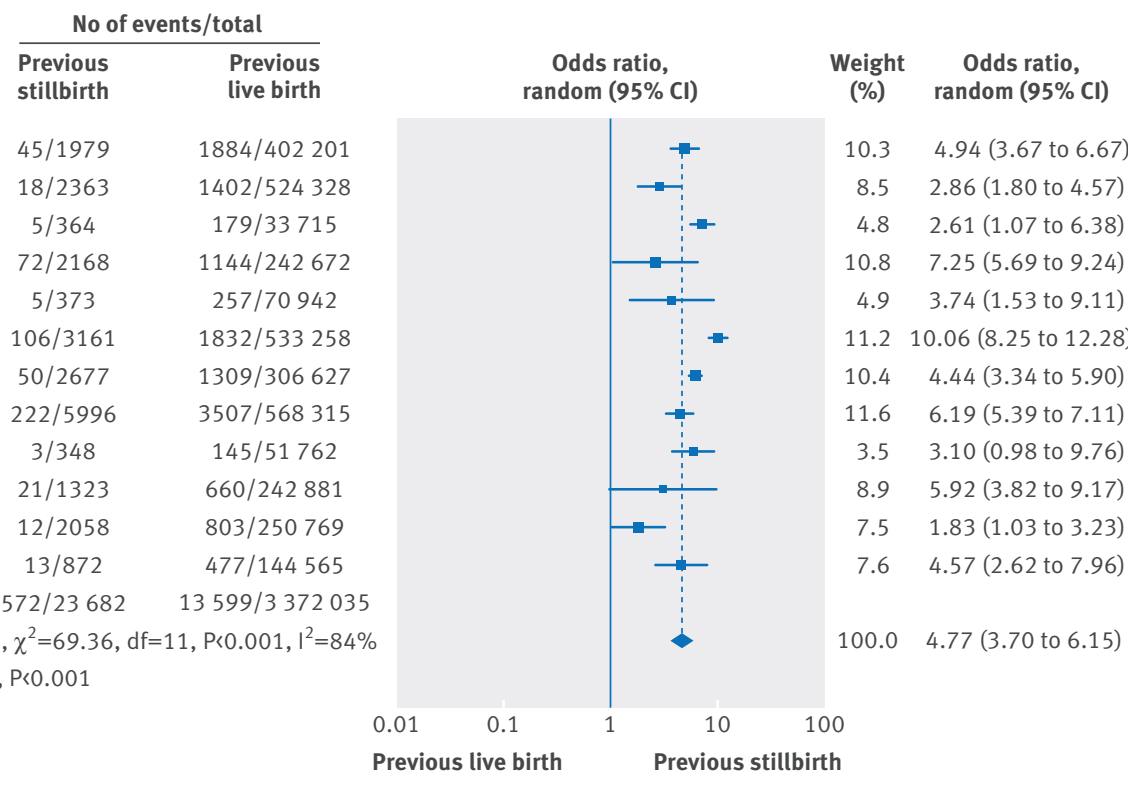

3.57 to 5.81). The supplementary file provides details of all sensitivity analyses.

\section{Population attributable risk}

We calculated the population attributable risk percentage to assess the proportion of subsequent stillbirth that is attributable to stillbirth in a first pregnancy. Based on unadjusted association measures, the result was $8 \%$.

\section{Publication bias assessment}

Although it is difficult to show evidence of asymmetry and therefore publication bias, visual inspection of a funnel plot (fig 5) showed a gap in the middle and bottom right of the plot suggesting that some smaller studies with large effects may be underrepresented.

\section{Discussion}

In this systematic review and meta-analysis, women who experienced a stillbirth in an initial pregnancy experienced nearly a fivefold increase in the odds of stillbirth in a subsequent pregnancy. Even when restricting the analysis to first and second pregnancies, the risk of stillbirth in the second pregnancy was increased if the first pregnancy ended in stillbirth. In the meta-analysis using adjusted odds ratios from primary studies the increased odds of recurrence remained, although it was slightly less than the unad-
Fig 4 | Random effects model (adjusted for various confounding factors) showing risk of stillbirth associated with previous stillbirth (confounders vary between studies). SCRNWG=Stillbirth Collaborative Research Network Writing Group

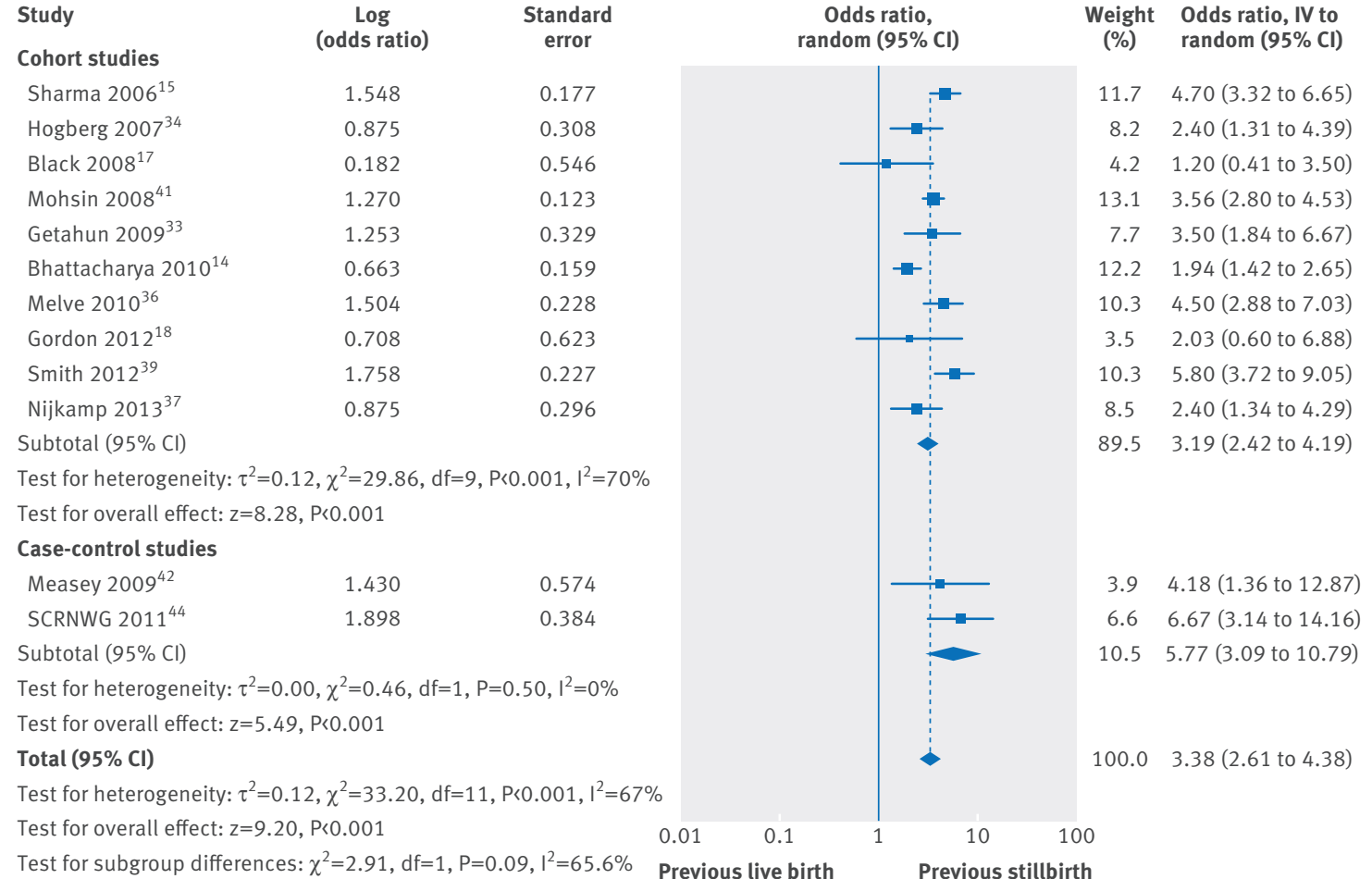


justed analysis. Where the primary studies had specifically looked at unexplained stillbirth, the evidence was less clear cut. Only two studies had looked at unexplained stillbirth in an initial pregnancy and any stillbirth (explained or unexplained) in the subsequent pregnancy and had found no increased risk. However, two other studies had specifically assessed unexplained stillbirth after any stillbirth (explained or unexplained) and reported a greatly increased risk of recurrence.

\section{Strengths and limitations of this review}

This systematic review and meta-analyses offers the first comprehensive synthesis of the available evidence on the association between stillbirth and unexplained stillbirth in a previous pregnancy and risk of recurrence. Meta-analyses were conducted (unadjusted and adjusted) that included data on a large number of women from high income countries to provide a quantitative summary of the results. The population based design of the included studies is a strength that promotes generalisability within countries as well as transferability of findings to other high income countries. Statistical heterogeneity of studies was substantial as evidenced by the high $\mathrm{I}^{2}$ statistic, and therefore as with all reviews of observational studies the findings should be interpreted with caution. Nevertheless, in all comparisons the estimates showed the same direction of effect, which suggests that the association is real. ${ }^{46}$

Systematic reviews of observational studies typically combine studies that are diverse both clinically and methodologically. As a result, heterogeneity between the results is to be expected..$^{46}$ In our analyses, primary studies differed in their definition of stillbirth and in their use of classification systems for determining cause of death and consequently in the classification of unexplained stillbirth. Moreover, methodological differences were apparent in their lack of consistency in tackling the effects of confounding. For instance, some studies adjusted for causal factors such as pre-eclampsia and placental abruption or preterm birth, which is not a confounder but rather in the causal path of stillbirth. After adjusting only for maternal characteristics, the estimated risk from these studies was reduced by $22 \%$ compared with the unadjusted risk. This suggests that much of the risk of recurrence is not explained by modifiable maternal factors, consistent with the Stillbirth

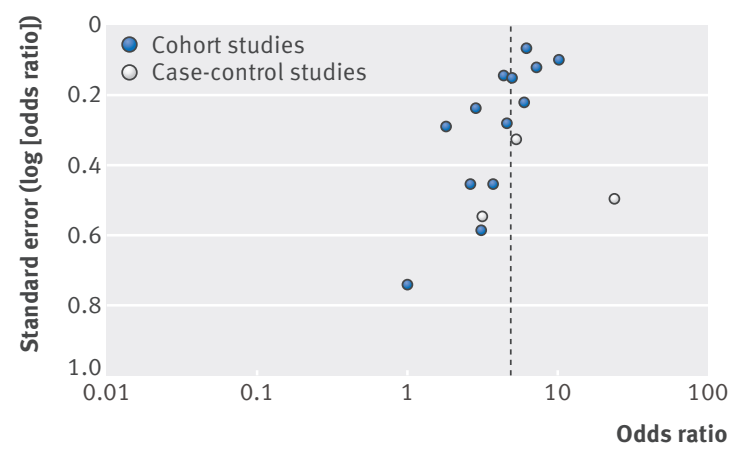

Fig 5 | Funnel plot to assess publication bias of included studies
Collaborative Research Network study, ${ }^{44}$ which showed that apart from the occurrence of previous stillbirth or pregnancy loss, risk factors known at confirmation of pregnancy (a combination of demographic and obstetric maternal characteristics) explained only a small amount of the risk of stillbirth. Nevertheless, the literature on the association between maternal obesity and stillbirth reports an increased risk of stillbirth among women who are obese compared with women of normal weight. ${ }^{47-53}$ Furthermore, a systematic review of observational studies conducted in high income countries showed that maternal overweight and obesity may have the greatest population attributable risk among modifiable maternal risk factors for stillbirth. ${ }^{54}$

For studies included in this meta-analysis, collection of important risk factors such as maternal body mass index and smoking was generally inconsistent, and information on alcohol intake was reported in only one study. ${ }^{33}$ Along with smoking, overweight and obesity are now thought to be causally associated with an increased risk of stillbirth, ${ }^{53}$ yet only three studies adjusted for body mass index, ${ }^{151744}$ and although most studies adjusted for smoking for many studies data were incomplete. Residual confounding from poor measurement of these could still explain at least part of the associations reported. Thus our findings might underestimate the risk of recurrence explained by modifiable risk factors.

The evidence surrounding the recurrence risk of unexplained stillbirth remains controversial owing to the few studies looking specifically at unexplained stillbirth, the small number of events in individual studies, and the variation in defining unexplained stillbirth.

Although no evidence of publication bias and selective reporting was found these are possible limitations for any systematic review, more so systematic reviews of observational studies. Therefore, despite the best efforts it is possible that not all studies were identified.

\section{Comparison with previous studies}

Despite a thorough and systematic literature search, no systematic review on this problem was identified. The literature on stillbirth has recently expanded ${ }^{3}$; however, studies that examined the recurrence of stillbirth remain scarce. Primary reports in the literature investigating the risk of stillbirth recurrence yielded inconsistent results, but most published studies suggest an increased risk for women with a history of stillbirth. However, when the previous stillbirth has been unexplained or when the sample size was small, adjustment for confounding factors made confidence intervals cross unity and no increased risk in subsequent stillbirth was found.

Inconsistency in the definition of unexplained stillbirth has also been recognised and it has been pointed out that truly unexplained stillbirths are those in which no cause of death can be found despite thorough postmortem examination. Gordon and colleagues made the decision a priori to only analyse data from 2002 because from that point all deaths were routinely classified using the perinatal death classification system of the Perinatal Society of Australia and New Zealand. This stillbirth classification system incorporates policy directives that 
include recommendations to discuss and offer postmortem examinations to every affected family, and for examination of the placenta. Even so, a postmortem examination was performed in only half of the stillbirths in the cohort. The authors draw attention to the low rate of postmortem examinations undertaken in unexplained stillbirths in New South Wales during the study period (30.8\%). Rates of postmortem examination for which parental consent is required are also low in the UK (around 45\%), although in Scotland as a result of ongoing commitment to improve procedure, rates of consent are higher.

Nijkamp and colleagues ${ }^{55}$ evaluated the subsequent pregnancy outcome after a previous stillbirth. The cause of death in both the index and the subsequent pregnancy was determined and compared using the Tulip classification system, the system developed and currently in use in the Netherlands for classifying cause of death. Of 163 women, 11 had a subsequent stillbirth, and of these at least six showed an association between the cause of death in both events.

Stillbirth is a relatively uncommon outcome in high income countries and recurrence even more so. Therefore to provide statistical power to observe the recurrence of unexplained stillbirth, large numbers of births are necessary in primary studies. Systematic reviews and meta-analyses can help overcome this deficiency in primary analyses.

\section{Implications for clinical practice and policy}

This research is relevant to public health and clinical practice because it adds to the body of evidence on stillbirth recurrence and can be used to counsel couples who are thinking of conceiving after a previous explained or unexplained pregnancy loss. Smoking and obesity are independently associated with an increased risk of stillbirth, and modification of these lifestyle factors may make a small but important reduction in the risk of recurrence. Current management of pregnancies should take account of pregnancy history and make use of prepregnancy counselling services. Based on the available evidence identified by this review, a stillbirth in an initial pregnancy was associated with an increased risk of a subsequent stillbirth, and pregnancies after a stillbirth should be closely monitored with a view to intervene at the first sign of fetal compromise. Consequently, clinical guidance from the UK Royal College of Obstetricians and Gynaecologists recommends that pregnant women with a previous stillbirth should be managed as high risk, yet many stillbirths result from non-recurrent events such as infection, problems with the umbilical cord, and isolated structural fetal anomalies. There is little evidence that this approach actually prevents stillbirth in the next pregnancy without increasing morbidity from unnecessary interventions.

The demand for international consensus on the use of a universal definition and classification for stillbirth for research purposes has been proposed for some time. To improve understanding of cause related and unexplained risk of stillbirth recurrence, large scale individual patient data meta-analyses are warranted, where uniform definitions and classifications can be applied. This systematic review highlights the scarcity of studies that examined the risk of stillbirth recurrence and shows the need for high quality multicentre studies using standardised definitions of stillbirth and unexplained stillbirth to add to current knowledge. Future research that stratifies women for the key confounding variables of obesity and smoking is needed to assess the impact of lifestyle modification on risk of recurrent stillbirth. In addition, to ascertain cause related recurrence, population based studies that examine the risk of subsequent stillbirth based on the initial cause of death are also needed. A clearly standardised universal definition of stillbirth for research and reporting practices is key issue if the methodological quality of stillbirth research is to be improved, be more comparable, and have more impact. Furthermore, a universal approach for stillbirth classification is fundamental for international comparisons to be meaningful and for progress towards the prevention of stillbirths.

\section{Conclusions and unanswered questions}

Stillbirths where no cause of death can be found continue to make a considerable contribution to perinatal mortality in high income countries. Much as stillbirth, and more so unexplained stillbirth, causes high levels of anxiety in future pregnancies for parents and birth attendants, it is a poorly studied complication of pregnancy. If parents are to be accurately informed about future risk, priority must be given to establishing the cause of fetal death.

We have shown that women who experience a stillbirth in their initial pregnancy have a higher risk of stillbirth in a subsequent pregnancy. Even after adjusting for potential confounding factors the increased risk remains. Risk of recurrent unexplained stillbirth is largely unstudied and therefore evidence about this remains controversial.

We thank Melanie Bickerton for her guidance on the search strategy. Contributors: KL conducted the searches, extracted the data, and wrote the first draft of the paper. NWS supervised and helped with the interpretation of the meta-analyses. GTJ assisted with data extraction and quality assessment and supervised KL. SB was responsible for formulating the review question, designing the study, conducting the literature searches independently, and supervising KL. All authors contributed intellectually to the writing or revising of the manuscript, and approved the final version. SB is the guarantor.

Funding: The University of Aberdeen acted as sponsors for this research project, but the findings and their interpretation in this study are the authors' own.

Competing interests: All authors have completed the ICMIE uniform disclosure form at www.icmje.org/coi_disclosure.pdf and declare: no support from any organisation for the submitted work; no financial relationships with any organisations that might have an interest in the submitted work in the previous three years; no other relationships or activities that could appear to have influenced the submitted work.

Ethical approval: Not required.

Data sharing: No additional data available.

Transparency: The lead author (SB) affirms that the manuscript is an honest, accurate, and transparent account of the study being reported; that no important aspects of the study have been omitted; and that any discrepancies from the study as planned (and, if relevant, registered) have been explained

This is an Open Access article distributed in accordance with the Creative Commons Attribution Non Commercial (CC BY-NC 4.0) license, which permits others to distribute, remix, adapt, build upon this work 
non-commercially, and license their derivative works on different terms, provided the original work is properly cited and the use is non-commercial. See: http://creativecommons.org/licenses/ by-nc/4.0/

1 Flenady V, Middleton P, Smith GC, Duke W, Erwich JJ, Khong TY, et al. Stillbirths: the way forward in high-income countries. Lancet 2011;377:1703-17.

2 Cousens S, Blencowe H, Stanton C, Chou D, Ahmed S, Steinhardt L, et al. National, regional, and worldwide estimates of stillbirth rates in 2009 with trends since 1995: a systematic analysis. Lancet 2011:377:1319-30

3 lancet.com. Stillbirths. 2011. www.thelancet.com/series/stillbirth.

4 Silver RM, Draper ML. Part 111: management of the patient with a stillbirth. Workup of the patient with a stillbirth. In: Spong CY, ed. Stillbirth: prediction, prevention and management. Wiley-Blackwell; 2011:187-202

5 Silver RM. Fetal death. Obstetr Gynecol 2007;109:153-67.

6 Flenady V, Froen JF, Pinar H, Torabi R, Saastad E, Guyon G, et al. An evaluation of classification systems for stillbirth. BMC Pregnancy Childbirth 2009;9:24.

7 Gardosi I, Kady SM McGeown P. Francis A, Tonks A. Classification of stillbirth by relevant condition at death (ReCoDe): population based cohort study. BMJ 2005;331:1113-7.

8 Korteweg FJ, Gordijn SJ, Timmer A, Erwich J], Bergman KA, Bouman K, et al. The Tulip classification of perinatal mortality: introduction and multidisciplinary inter-rater agreement. BJOG 2006;113:393-401.

9 Froen JF, Pinar H, Flenady V, Bahrin S, Charles A, Chauke L, et al. Causes of death and associated conditions (Codac): a utilitarian approach to the classification of perinatal deaths. BMC Pregnancy Childbirth 2009;9:22.

10 Chan A, King J, Flenady V, Haslam R, Tudehope D. Classification of perinatal deaths: development of the Australian and New Zealand classifications. J Paediatr Child Health 2004;40:340-7.

11 Flenady V, King J, Charles A, Gardener G, Ellwood D, Day K, et al. PSANZ Clinical Practice Guideline for Perinatal Mortality. The Perinatal Society of Australia and New Zealand (PSANZ) Perinatal Mortality Group. Apr 2009.

12 Fretts RC. Etiology and prevention of stillbirth. Obstet Gynecol 2005;193:1923-35.

13 Cnattingius S, Stephansson O. The epidemiology of stillbirth. Semin Perinatol 2002;26:25-30.

14 Bhattacharya S, Prescott G], Black M, Shetty A. Recurrence risk of stillbirth in a second pregnancy. BJOG 2010;117:1243-7.

15 Sharma PP. Is race a determinant of stillbirth recurrence? Obstet Gynecol 2006;107(2, Part 1):391.

16 Samueloff A, Xenakis EM, Berkus MD, Huff RW, Langer O. Recurrent stillbirth. Significance and characteristics. J Reprod Med 1993;38:883-6.

17 Black M, Shetty A, Bhattacharya S. Obstetric outcomes subsequent to intrauterine death in the first pregnancy. BJOG 2008;115:269-74.

18 Gordon A, Raynes-Greenow C, McGeechan K, Morris J, Jeffery H. Stillbirth risk in a second pregnancy. Obstetr Gynecol 2012;119:509-17

19 Stroup DF, Berlin JA, Morton SC, Olkin I, Williamson GD, Rennie D, et al. Meta-analysis of observational studies in epidemiology: a proposal for reporting. JAMA 2000:283:2008-12.

20 World Bank. Country and lending groups. World Bankorg/. 2013 http://data.worldbank.org/about/country-classifications/ country-and-lending-groups.

21 UKCRN. UK Clinical Research Network study portfolio. 2013. http:// public.ukcrn.org.uk/.

22 MIDIRS. MIDIRS (Midwives Information and Resource Service). 2013. http://midirs.org/.

23 ProQuest. Dissertations and theses: UK and Ireland database. 2013. http://proquest.com/products_umi/dissertations/.

24 Critical Appraisal Skills Programme: 11 questions to help you make sense of case-control study. 2013. www.casp-uk.net/ wp-content/uploads/2011/11/CASP-Case-Control-StudyChecklist-31.05.13.pdf.

25 Critical Appraisal Skills Programme: 12 questions to help you make sense of cohort study. 2013. www.casp-uk.net/wp-content/ uploads/2011/11/CASP-Cohort-Study-Checklist-31.05.13.pdf.

26 Cochrane Collaboration. Review Manager (RevMan) [Computer Program]. Version 5.2. Cochrane Collaboration. 2012

27 DerSimonian R, Laird N. Meta-analysis in clinical trials. Control Clin Trials 1986;7:177-88.

28 Mantel N, Haenszel W. Statistical aspects of the analysis of data from retrospective studies of disease. J Natl Cancer Inst 1959;22:719-48.

29 Greenland S. Quantitative methods in the review of epidemiologic literature. Epidemiol Rev 1987;9:1-30

30 Cochrane Collaboration. Evidence-based health care and systematic reviews. 2013. www.cochrane.org/about-us/evidence-based-health-care.
31 Levin ML. The occurrence of lung cancer in man. Acta Unio Int Contra Cancrum 1953;9:531-41.

32 Light R, Pillemar D. Summing up: the science of reviewing research. Harvard University Press; 1984.

33 Getahun D, Lawrence JM, Fassett MJ, Strickland D, Koebnick C, Chen W, et al. The association between stillbirth in the first pregnancy and subsequent adverse perinatal outcomes. Obstet Gynecol 2009;201:378.e1-378.e6.

34 Hogberg L, Cnattingius S. The influence of maternal smoking habits on the risk of subsequent stillbirth: is there a causal relation? BJOG 2007;114:699-704

35 Lykke JA, Paidas MJ, Langhoff-Roos J. Recurring complications in second pregnancy. Obstet Gynecol 2009;113:1217-24.

36 Melve KK, Skjaerven R, Rasmussen S, Irgens LM. Recurrence of stillbirth in sibships: population-based cohort study. Am J Epidemiol 2010;172:1123-30.

37 Nijkamp J, Ravelli A, Schaaf J, Groen H, Erwich JJ, Mol B. Recurrence risk of stillbirth in a subsequent pregnancy: a population-based cohort study. Am J Obstetr Gynecol 2013;208(Suppl 1):S63-4.

38 Robson S, Chan A, Keane RJ, Luke CG. Subsequent birth outcomes after an unexplained stillbirth: preliminary population-based retrospective cohort study. Aust N Z J Obstet Gynaecol 2001;41:29-35.

39 Smith $\mathrm{G}$. The relationship between cause and timing of previous stillbirth and the risk of stillbirth in second pregnancies. Am J Obstetr Gynecol 2012;206(Suppl 1):S64.

40 Patterson JA, Ford JB, Morris JM, Roberts CL. Trends and recurrence of stillbirths in NSW. Aust N ZJ Public Health 2014;38:384-9.

41 Mohsin M, Jalaludin B. Influence of previous pregnancy outcomes and continued smoking on subsequent pregnancy outcomes: an exploratory study in Australia. BJOG 2008;115:1428-35.

42 Measey MA, Tursan d'Espaignet E, Charles A, Douglass C. Unexplained fetal death: are women with a history of fetal loss at higher risk? Aust N Z J Obstet Gynaecol 2009;49:151-7.

43 Ofir K, Kalter A, Moran O, Sivan E, Schiff E, Simchen MJ. Subsequent pregnancy after stillbirth: obstetrical and medical risks. J Perinat Med 2013;41:543-8.

44 Stillbirth Collaborative Research Network Writing Group. Association between stillbirth and risk factors known at pregnancy confirmation. JAMA 2011;306:2469-79.

45 Whitfield CR, Smith NC, Cockburn F, Gibson AAM. Perinatally related wastage? A proposed classification of primary obstetric factors. BJOG 1986;93:694-703

46 Thompson SG. Why sources of heterogeneity in meta-analysis should be investigated. $B M$ / 1994:309:1351-5.

47 Aune D, Saugstad O, Henriksen T, Tonstad S. Maternal body mass index and the risk of fetal death, stillbirth, and infant death: A systematic review and meta-analysis. JAMA 2014;311:1536-46.

48 Chu SY, Kim SY, Lau J, Schmid CH, Dietz PM, Callaghan WM, et al. Maternal obesity and risk of stillbirth: a metaanalysis. Obstet Gynecol 2007;197:223-8

49 Cnattingius S, Lambe M. Trends in smoking and overweight during pregnancy: prevalence, risks of pregnancy complications, and adverse pregnancy outcomes. Semin Perinatol 2002;26:286-95.

50 Nohr EA, Bech BH, Davies MJ, Frydenberg M, Henriksen TB, Olsen. Prepregnancy obesity and fetal death: a study within the Danish National Birth Cohort. Obstet Gynecol 2005;106:250-9.

51 Reddy UM, Laughon SK, Sun L, Troendle J, Willinger M, Zhang J. Prepregnancy risk factors for antepartum stillbirth in the United States. Obstet Gynecol 2010;116:1119-26

52 Stacey T, Thompson J, Mitchell E, Ekeroma A, Zuccollo J, McCowan L. Relationship between obesity, ethnicity and risk of late stillbirth: a case control study. BMC Pregnancy Childbirth 2011;11:3.

53 Villamor E, Cnattingius S. Interpregnancy weight change and risk of adverse pregnancy outcomes: a population-based study. Lancet 2006;368:1164-70

54 Flenady V, Koopmans L, Middleton P, Froen JF, Smith GC, Gibbons K, et al. Major risk factors for stillbirth in high-income countries: a systematic review and meta-analysis. Lancet 2011:377:1331-40.

55 Nijkamp J, Korteweg F, Holm J, Timmer A, Erwich JJ, van Pampus M. Subsequent pregnancy outcome after previous foetal death. Eur J Obstet Gynecol Reprod Biol 2013:166:37-42.

Appendix: Updated search strategies Appendix: Studies excluded on basis of full text Appendix: Details of sensitivity analyses Appendix table 1: Number of potentially avoidable deaths in exposed population if babies had same risk as baseline group unadjusted analysis Appendix tables 2 and 3: Quality assessment of included cohort and case-control studies 